\title{
El documental interactivo y transmedia: narrar en clave local, ver en clave global
}

\author{
Carlos Obando Arroyave \\ Pontificia Universidad Javeriana, Colombia \\ obando-luis@javeriana.edu.co \\ https://orcid.org/0000-0003-4838-3808
}

\section{The interactive and transmedia documentary: narrate in a local key, see in a global key}

\begin{abstract}
RESUMEN ABSTRACT
Ante los avances tecnológicos y el cambio en la forma de consumir información, los medios de comunicación se enfrentan a la necesidad de reinventarse, surgen nuevos formatos, nuevas narrativas y nuevos productos de no-ficción y periodísticos adaptados a la era de la multimedialidad, la hipertextualidad y la interactividad, categorías claves para entender el cambio en el ecosistema digital actual. Este texto pone de manifiesto las nuevas posibilidades creativas y de producción que se abren con la llegada y expansión de las tecnologías digitales, así como con el diseño y apropiación de las narrativas transmedia en ámbitos socio-comunitarios y territorios locales. A nivel metodológico y a través de la selección de cuatro ejemplos representativos del webdoc o documentales interactivos y transmedia, desarrollados en o con Latinoamérica (Beyond the map, 2016; Mujeres en venta, 2015; Pregoneros de Medellín, 2015; Webdoc transmedia: El Congost visto por el Congost, 2015) propone una mirada a los cambios que se vienen dando en el formato documental o reportaje de no-ficción diseñado para ser consumido en la web, y en los mecanismos, herramientas y tecnologías que tenemos hoy en día para contar historias que rompen las estructuras tra-

Faced with technological advances and the change in the way of consuming information, the media are faced with the need to reinvent themselves, new formats, new narratives and new non-fiction and journalistic products are emerging adapted to the era of multimedia, the hypertextuality and interactivity, key categories to understand the change in the current digital ecosystem.

This text highlights the new creative and production possibilities that open up with the arrival and expansion of digital technologies, as well as with the design and appropriation of transmedia narratives in socio-community settings and local territories. At a methodological level and through the selection of four representative examples of the webdoc or interactive and transmedia documentaries, developed in or with Latin America (Beyond the map, 2016; Women for sale, 2015; Town criers of Medellín, 2015; Webdoc transmedia: El Congost seen by Congost, 2015) it proposes a look at the changes that have been taking place in the documentary format or non-fiction report designed to be consumed on the web, and in the mechanisms, tools and technologies that we have today to tell stories that break the traditional structures of audiovisual creation and consumption.
\end{abstract} dicionales de creación y consumo audiovisual.

PALABRAS CLAVE KEYWORDS

Webdoc; Multimedialidad; Documental interactivo; Hipertexto; Interactividad; Narrativas transmedia; No-ficción.

Webdoc; Multimediality; Interactive documentary; Hypertext; Interactivity; Transmedia narratives; Non-fiction. 


\section{La expansión de la mirada o la pérdida del control}

La llegada y expansión de las Tecnologías de la Información y la Comunicación (TIC), y sobre todo la denominada web 2.0 ha supuesto una profunda transformación de las maneras de contar y consumir historias. Guiados por los nuevos dispositivos tecnológicos, nuevas pantallas y formas de creación de contenidos, el cambio en el mundo digital nos está mostrando un reordenamiento de las viejas formas de producción ahora resignificadas en las nuevas competencias de esta re-evolución. Me explico: aquello que parecía perdido u olvidado a causa de los avances de la sociedad tecnológica, reaparece ahora más potente que nunca reinterpretado en un nuevo contexto y una nueva forma para ser contado.

Los modelos de creación y producción artesanal olvidados por las industrias del entretenimiento, la fabricación en serie de las grandes cadenas de producción, la estandarización de los modelos de producción industrial y los valores de una cultura basada en la profesionalización de las disciplinas y las técnicas llevadas a la potente y desarrollada industria del cine y la televisión en el siglo $X X$, se ven ahora amenazadas por el resurgimiento de un mundo amateur, un mundo artesanal más vivo que nunca y más dotado que antes de herramientas que les permite incluso competir con los contenidos canon de las grandes factorías. Pienso en los Youtubers como el mejor ejemplo de lo que intento explicar, pero más allá, todos aquellos pro-activos y re-activos usuarios que conectados a pantallas aplican sus conocimientos obtenidos generalmente a través de esas mismas pantallas (y no de la escuela) a partir de los cientos de tutoriales que pueblan el ciberespacio. El artesano, pues, vuelve a estar de moda, pero ahora en vez de trabajar con esos materiales de antes como la madera el barro o el hierro, utilizan materiales intangibles como los bits y las datas del mundo tecnológico.

Las nuevas tecnologías de la comunicación, pues, vienen transformando radicalmente las formas de apropiación de la cultura, como también las modalidades de creación y producción de los contenidos culturales, pues las facultades hoy no dependen del dominio del medio o de la propiedad sobre los soportes como ocurría en la sociedad industrial con grandes cadenas de televisión, con enormes recursos tecnológicos o monumentales edificios que albergaban -o albergan- cientos de trabajadores en diarios y revistas impresas. Hoy el acceso a múltiples herramientas y aplicaciones de la web remodelan la relación entre sujeto/objeto, al proponer nuevas subjetividades y relaciones del individuo con el mundo. El nuevo ciudadano empoderado de estas teletecnologías de la información y la comunicación construye formas diversas de ciudadanía, quizás más democráticas, a partir de las prácticas ejercidas en el ciberactivismo y en el modelo open source o contributivo de la Internet 2.0, o en la cultura hacker, donde tiene sus raíces culturales Internet. Para Manuel Castells (2001), es allí donde aparece esta nueva élite de activistas y libertarios dotados de un arma tecnológicamente poderosa que utilizan para derrotar al capitalismo y combatir las exclusiones nacidas en la sociedad industrial y capitalista. Vivimos, pues, a las puertas de una nueva generación que domina estas herramientas, utiliza plataformas digitales como lugar de experimentación modificando los patrones de comportamiento que traíamos con las viejas maneras de crear y producir, y con una aparente disposición al trabajo colaborativo.

El nuevo modelo comunicativo nos exige mirar los nuevos retos que tenemos con está profunda transformación de los modelos de creación, producción, distribución y consumo de contenidos culturales. La cultura audiovisual de hoy no corresponde para nada a la que teníamos hace poco tiempo en el panorama analógico. Se empodera transformándose y modificando las viejas formas de consumo del cine y la televisión. Nada es lo que era, Netflix y YouTube han venido a hacérnoslo visible, la televisión se desterritorializa, es bajo demanda y sin restricciones de horarios transmite sin ataduras programáticas ni parrillas encorsetadas.

El mundo audiovisual, qué duda cabe, es ahora digital y se encuentra cada vez más cómodo en esas formas de creación, distribución y consumo mediadas por el nuevo medio. Las estructuras abiertas y descentradas de la producción, la creatividad redistribuida, la transmedialidad de los relatos y las posibilidades casi infinitas de grabación y manipulación gracias a los novedosos software y aplicaciones del panorama tecnológico actual, están dejando claro que el futuro inmediato de la creación no reside en las tecnologías en sí mismas, sino en las capacidades tecno-creativas de los usuarios que alimentan constantemente la red con imágenes y videos con valor añadido a la producción inicial.

Pero también la época marca nuevos comportamientos en los que el televidente toma al mando y decide cuándo, dónde y porqué medios o plataformas ve el contenido televisivo. Si los ve uno a uno como en el medio televisión, si los mira todos juntos de una sentada usando el streaming, o si a través de foros o plataformas fan se entera como fue visto el contenido en otros países donde ya fue exhibido y que nuevos aportes al contenido canon le revela ese otro nivel de contenidos fandom que se crean y distribuyen por la red.

Estamos, pues, claramente ante la pérdida de control del productor o emisor en un nuevo modelo tecno-comunicacional que plantea cambios al modelo vertical de producción y consumo que traíamos hasta ahora. $Y$ esto es precisamente el documental interactivo y transmedia o webdoc, un formato que trae nuevos aportes que están poco a poco permeando las narrativas digitales y que viene cargado de nuevas características que constituyen la materia prima de los nuevos formatos o storytelling de la web. 
Efectivamente, la interactividad, es el primero de sus aportes, nuevo porque modifica el rol del emisor y del receptor de los mensajes poniéndolos en un relación horizontal de producción de contenidos y de interacciones con el contenido, las interfaces o los mismos productores; la reticularidad es el segundo gran aporte, porque pasa por la difusión de mensajes en ese mismo nivel horizontal de muchos a muchos y no de uno a muchos como ocurría en el viejo sistema lineal o analógico de la comunicación; la hipertextualidad, el tercer aporte importante, porque permite el diseño de mensajes con lenguajes diferentes e interconectados a través de hiperenlaces en la red; $y$, finalmente, la transmedialidad como la posibilidad de transmitir un contenido de forma fragmentada y expandida, utilizando múltiples plataformas y a través de diversos medios y lenguajes. En resumen; es en toda esta urdimbre o nueva gramática digital donde se cuece una expansión de la mirada que revisaremos de manera puntual y con ejemplos muy ilustrativos en este nuevo formato; el webdoc o documental interactivo y transmedia.

\section{Entre interactividad e inmersión: las narrativas digitales}

Está claro que no es solo tecnologías o dispositivos, Internet está diseñando nuevos escenarios para abordar la realidad, para hablar de ella de una manera distinta, o quizás para cubrir la realidad de nuevos imaginarios potenciados por la convergencia tecnológica. Más aún, el entrecruzamiento de tecnologías permite que desde un mismo dispositivo o gadget tecnológico conectado a una red inalámbrica se puedan tomar fotografías, grabar videos y audios, escribir textos o mezclar la producción propia con la ajena. Efecto que nació en el momento mismo en que transitamos de la llamada web 1.0 a la web 2.0, interactiva, bidireccional y multiplataforma.

Prensa, radio y televisión están hoy presentes en Internet y lo hacen a veces enfrentándose a una lucha por la supremacía de las audiencias hiperconectadas, aprovechan la capacidad irradiadora de la red para colarse en lugares y usuarios a los que no accederían por los conductos tradicionales de la difusión, es decir pretenden más calar en las nuevas audiencias y los nuevos consumos que migrar las que ya tienen conectadas y acostumbradas a los viejos medios. Pero Internet es un medio de comunicación en sí mismo, un metamedio que los incluye a todos y no un simple soporte en el que se adaptan de manera cómoda los medios tradicionales. En Internet la información se distribuye de otra manera, de forma reticular e interactiva, como ya lo dijimos, de forma hipertextual como no ocurre en los medios analógicos, y de forma transmedial al cruzar diferentes plataformas, lenguajes y diversos dispositivos tecnológicos.

Ahora bien, Internet se convierte en el nuevo ecosistema tecnológico que potencia la distribución de toda clase de mensajes; sonidos, imágenes y textos, sin un único centro de control, lo que favorece una comunicación en red y globalizada que repercute en el papel cada vez más protagónico que empiezan a tener las audiencias locales y las experiencias barriales, que no sólo ejercen como lectores o espectadores a la vez, sino como productores del relato y constructores de sentido:

lo que hemos de asumir es que estamos en el tramo final de la escritura como criterio único de civilización, comunicación y creación cultural, como memoria privilegiada de los aprendizajes y experiencias históricas. Vivimos ya bajo el signo de múltiples lenguajes y de sus realidades; y es evidente que éstos configuran nuestro modo de vivir. (Nadin, M., 2003 p. 172)

El reto en el escenario tecno-social y comunicativo es significativo para la construcción de identidades, si partimos nuestro análisis de los cientos de website o proyectos multimedia que se crean en la web y despliegan y comparten contenidos locales o específicos, generados y producidos por los propios ciudadanos convertidos ahora en productores audiovisuales, periodistas 2.0 y programadores de código abierto y open source. 0 como dice Vilches (2001) los usuarios dejan de ser objetos de manipulación, para transformarse en sujetos que manipulan. Ya no están pues a merced de los grandes medios de comunicación o de los organismos institucionalizados que controlaban, filtraban y decidían que, cómo y cuándo publicar, sino que ahora tienen las herramientas que les permite crear, distribuir contenidos generados por ellos mismos sin el filtro del editor o la mirada corporativa.

Y ésta es quizá la característica más sobresaliente en esta nueva era de Internet; la relación bidireccional entre los lectores y los medios de comunicación, y la aparición de nanomedios o micromedios que se deslindan de los modelos tradicionales para producir sus propios contenidos. En el documental interactivo, aquel de corte social, barrial o comunitario, la calle se traslada a la pantalla y las historias más locales, a veces conmovedoras otras desconocidas o simplemente invisibilizadas por la gran prensa se revelan, se convierten en historias digitales, conquistan el ciberespacio y se instalan en la nube para ser vistas una y otra vez, compartidas, estudiadas. En fin; así ocurre en cientos de documentales interactivos que empiezan a alimentar la web, muchos de ellos diseñados no por grandes productoras audiovisuales o medios de comunicación reconocidos, sino más bien por productores free lance, activistas sociales, profesores e investigadores y pequeñas organizaciones sociales o comunitarias. Proyectos muchos de ellos de gran factura tanto desde del diseño de producción y gestión de contenidos, como desde las interfaces creadas para soportar y distribuir dichos contenidos, en la mayoría de los casos, pensados más para ser navegados que vistos, escuchados o Leídos. 


\section{El documental interactivo y transmedia; el nuevo desafío narrativo en Latinoamérica}

Documental interactivo, webdoc, documental expandido, documental $360^{\circ}$, o incluso no-ficción interactiva, son términos para referirse, aunque con matices, al mismo formato; un documental que explora y explota la naturaleza de la nueva web 2.0. Ponerse frente a la pantalla y activar la mirada para tomar decisiones de navegación a través de los diversos nodos y anclajes del relato documental, es la operación por la que estamos hablando de un nuevo formato que nada tiene que ver con el documental en línea que exigía un espectador atento y pasivo. El nuevo documentalista es ahora un realizador-arquitecto de contenidos que tiene en su materia prima diversos lenguajes para contar su historia: video, audio, texto, infografías, cartografías, datos que debe saber poner en escena en una interfaz-pantalla y conjugar de forma hipertextual. Quizás y, eso es lo que estamos viendo en la producción digital del nuevo formato; aprender a narrar en clave local para ser visto y consumido en clave global.

El usuario debe identificar diferentes lógicas de documentación de la realidad y percibir esta realidad desde otra perspectiva que pone en evidencia nuevos modelos de la subjetividad, adquiriendo un rol determinante en un diálogo entre productor, obra y espectador, ya sea a través de simples comentarios o como co-creador y consumidor activo. El espectador, pues, participa de manera más activa convirtiendo la experiencia visual, a partir de la navegación y la inmersión, en un juego relacionado con el entretenimiento y la diversión pudiendo incluso, según sea el diseño de la plataforma que soporta el contenido, modificar o ampliar el contenido creando lo que se conoce como documental expandido, es decir un documental que va creciendo con nuevos contenidos o incluso con el aporte de los usuarios que lo ven.

Hoy la tecnología digital abre nuevos campos al documentalista y por tanto al trabajo audiovisual en las comunidades y localidades de todo el mundo; crea el acceso a nuevas fuentes, a un sin número de bases de datos y al almacenamiento y diseño personalizado y fragmentado de la información obtenida. El resultado es una producción multimedia en la que el usuario podrá entrar en el documental haciendo lecturas no-lineales; abriendo o cerrando el material según su propio criterio o deseo; recorriéndolo a su ritmo y seleccionando las diversas posibilidades que le aporta las estructuras hipertextuales de la cultura digital. En resumen, estamos asistiendo a las narrativas complejas, profundas y expandidas, cultura audiovisual mosaico que se cuenta de otra manera. En síntesis, un documental en formato multimedia diseñado para ser navegado por la web y que plantea diversas opciones de recorrido al usuario. Una interactividad que explora el interés de los usuarios y conecta con la diversidad de audiencias digitales que tenemos.
Pero fue, quizás, la llegada de YouTube en 2005 el determinante para la implantación de este tipo de narrativas. No es un secreto que la plataforma de video más conocida del mercado digital revolucionó de manera definitiva la creación, la distribución y el consumo audiovisual. La tecnología que trajo consigo el streaming es sin lugar a duda el invento más importante de la cultura 2.0, no sólo porque actúa como servidor gratuito de ingente material audiovisual, sino porque desde la compra de la plataforma de video por parte de Google en 2008 no ha dejado de perfeccionarse, creando una interfaz sencilla, de fácil manejo y modificable al dejar liberado su código html. $Y$ en 2008 otro momento clave cuando YouTube incorpora en su plataforma el video interactivo que permite saltar de un video a otro o crear enlaces a otras fuentes de datos a partir de la herramienta videoanotaciones, una interfaz que permite las superposiciones textuales a partir de la inserción de enlaces en la línea del tiempo del video lineal.

Además, YouTube incluye una guía de herramientas para creadores donde comparte recursos para ayudar a crear un mejor contenido, construir bases de fans, medir audiencias, editar vídeo on-line, crear subtítulos y utilizar la enorme cantidad de audios de su biblioteca personalizada y gratuita. Es decir, una cantera enorme de herramientas e ideas para la creación y producción de videos interactivos que viene siendo bien capitalizado por creadores que utilizan la plataforma para crear y exponer sus storytelling con finales alternativos que deben ser seleccionados por usuarios activos conectados a la pantalla.

Sabemos que el documental tradicional es lineal, es decir, sabemos dónde inicia y donde termina la historia narrada, conocemos de entrada como se consume y sin mayores dificultades o esfuerzo físico recorremos la historia creada por el autor de la obra. En este caso es el autor quien decide y controla todo el tiempo el discurso narrativo, su recorrido está perfectamente delimitado. Por el contrario, y esta es la novedad, en el documental interactivo empezamos en uno o varios puntos de partida propuestos por el autor y vamos encontrando bifurcaciones y caminos alternativos siguiendo la ruta trazada en la pantalla y recorrida de muchas maneras, tantas como espectadores tengamos. En este sentido la decisión de cómo verse el contenido, no es del autor, sino del interactor conectado a la pantalla. Por lo tanto, cuando en un documental lineal existe una historia que no es posible alterar en su orden, en el interactivo diferentes historias son posibles y varios desarrollos del contenido, de tal forma que no hay un orden definido y cualquiera que exista puede ser modificado. La forma no lineal diseñada en estructuras reticulares y experiencias dispuestas a la imaginación, la exploración y la inmersión, se expande en el espacio de la pantalla de la web donde organiza conexiones múltiples y niveles personalizados de consumo. 
Los desafíos para el periodismo y la no ficción interactiva y transmedia están apenas en una fase inicial en Latinoamérica, si nos atenemos a la producción de este tipo de formatos provenientes de los grandes medios, históricos canales de televisión o estructuras de producción canónicas. Los medios atraviesan hoy un periodo de crisis, porque todavía no encuentran la manera de volverse rentables en el mundo digital. El desarrollo de productos digitales e interactivos con alto desarrollo técnico no está aún resuelto, probablemente porque el esfuerzo en tiempo y dinero, además de la necesidad de contar con equipos y profesionales altamente capacitados, polivalentes e interdisciplinares no son vistos como la forma de salir de dicha crisis.

La industria en general aún no encuentra las oportunidades de negocio de este tipo de formatos y quizás por esta razón los canales de televisión en Latinoamérica, Llamados a liderar este tipo de producción, siguen anclados en los formatos más tradicionales (no solo documentales) que les ha brindado éxito y fortuna. Las nuevas producciones aún se miran con recelo y las producciones que se abren paso en el universo transmedia suelen provenir de investigadores y profesores de universidades latinoamericanas o de emprendimientos personales, sociales y privados o de experiencias individualizadas de productores independientes que mediante diversos recursos crean y producen este tipo de formatos.

Se percibe, en definitiva, una falta de compromiso o entusiasmo por parte de los canales, productoras y medios de comunicación tradicionales para generar nuevas posibilidades de creación y producción que pasen por este tipo de formatos disruptivos y pensados desde el escenario tecno-comunicacional. Quizás también, valga decirlo, las empresas periodísticas, llamadas a producir este tipo de formatos transmediales no integran aun sus equipos de producción, ni se articulan desde sus competencias para producir contenidos en múltiples lenguajes, medios y plataformas. El trabajo en las unidades de redacción y producción sique siendo, con algunas excepciones, compartimentado, individualista y claramente disgregado. En resumen, la industria de medios está poco implicada en este proceso, y en este sentido tenemos que concluir que el camino para este formato en buena parte de los países que conforman esta región desde México hasta Chile apenas comienza.

\section{Una arbitraria selección de webdocs en Latinoamérica}

Para explicarnos todo lo anterior, proponemos a partir de aquí el análisis de cuatro productos interactivos, inmersivos y transmedia de no-ficción, revisando algunos ejemplos de proyectos hechos o vinculados a Latinoamérica, así como una conceptualización y análisis que interprete el camino propuesto por estos modelos narrativos y su importancia en el panorama creativo y de producción de este formato. Intentamos recoger proyectos diversos producidos en distintos países y ecosistemas mediáticos diferentes, así como formas de producción y financiación también distintas. Veamos:

\subsection{Beyond the map (Além do Mapa): explore el mundo de las favelas en $360^{\circ}$ como nunca antes}

Beyond the map: explore el mundo de las favelas en $360^{\circ}$ como nunca antes. 'Es un proyecto lanzado dos días antes del inicio de los Juegos Olímpicos de 2016 en Brasil, país con más de 200 millones de habitantes. El documental construye una cartografía de la inmensa ciudad de Rio de Janeiro donde viven cerca de siete millones de ciudadanos y utiliza la plataforma Google Arts \& Culture para penetrar de forma ingeniosa en la esencia de un territorio con profundas fisuras y enormes desigualdades. La historia se cuenta sin falsas apariencias y sin los aspavientos del gran cine acostumbrado a darnos las imágenes comerciales, exóticas y sensacionalistas de las favelas que nos retratan el lugar y nos comercializan la pobreza. En este caso los autores ruedan con cámaras novedosas y tecnologías emergentes: $360^{\circ}$, Go Pro y Drones, y nos adentran en los escenarios de estas favelas para documentar, navegar e imaginar esta ciudad donde viven millones de ciudadanos anónimos con historias de vida de personajes realmente inspiradores.

El documental de realidad virtual en formato de video de $360^{\circ}$ grados nos permite navegar en todas las direcciones, tomar la ruta que queramos y proponer consumos personalizados, además de sentirse todo el tiempo viviendo la experiencia del recorrido señalado. Una serie de videos documentales se vinculan a geolocalizaciones en Google Maps que el espectador puede navegar de forma aleatoria o siguiendo la secuencia narrativa de ocho historias establecidas por los creadores y productores del proyecto.

Los episodios con una duración entre 4 y 5 minutos se conectan a través de una especie de road movie que nos lleva a determinados lugares donde emergen las historias de diversos personajes llevados por una conductora, la actriz Bianca Comparato que hace la versión en inglés y un conductor, el actor Jonathan Haagensen, que hace la versión en portugués.

\subsubsection{Las historias mapeadas e inmersivas}

En la primera historia nos subimos a un mototaxi y a través de una Go Pro nos internamos en las estrechas callejuelas de la favela desde la que observamos el paisaje humano de esta localidad. Como lo enuncian: "Súbete a la parte trasera de un mototaxi para un emocionante viaje de $360^{\circ}$ hacia el corazón de São Carlos mientras corremos hacia la cima de una de las favelas más antiguas de Río. Sienta lo que es moverse por las favelas como un lugareño".

Un cámara Drone nos transporta a la segunda historia, la de Paloma una mulata habitante de Maré, una de las favelas 
más peligrosas de Río para contarnos como esta joven mujer sortea su sueño de trabajar con inteligencia artificial y tecnologías digitales. El computador se convierte en su mejor arma para desarmar los corazones de la violencia que en la zona no da respiro. Asiste a la universidad a estudiar informática, porque Paloma quiere demostrar que aun siendo negra y mujer y viviendo en una favela puede llegar a ser informática. La historia nos revela este desafío.

La Drone vuelve a llevarnos por los extensos parajes de Rio para conocer a Luís, un adolescente que vive en el Complejo do Alemão y que sueña con convertirse en bailarín de la prestigiosa compañía de danza del Teatro Municipal de Río de Janeiro. Es la tercera historia que remarca el coraje de bailar aun en medio de las dificultades. El joven Luis nos adentra en su barrio, nos sube al transporte público, nos mete en su casa y nos lleva a la academia de baile local para hacernos danzar al ritmo de su historia narrada por él, su madre y sus profesores, justamente enfrente de la fachada del majestuoso edificio de la danza de Rio.

El poder del mar es la siguiente historia, la de Ricardo un veterano surfista que saca a los niños de la miseria de las calles para enseñarles a dominar las corrientes y olas del Atlántico Sur. La cámara se remonta en las alturas para llevarnos a lo más alto de la favela Rocinha, mostramos un paisaje colorido y dejarnos entrar a la escuela de surfing en un paisaje de playa dominado por los cerros del Pao de Azúcar enmarcados en el fondo de la ciudad.

O Vidigal es otra comunidad llena de color y creación que se destaca en Rio porque sus residentes usan el arte, la música y la danza para cambiar sus vidas o al menos darle una mejor forma y apariencia a la favela. La experiencia vivida a través del $360^{\circ}$ nos descubre cómo los residentes de este territorio, mujeres en particular, tocan los tambores y danzan mientras nos describen como la fuerza femenina está allí para transformar la vida de sus habitantes. También conoceremos en esta inmersión $360^{\circ}$ a Azamat, un grupo de rap del lugar conformado por Ramon y Dhonata que nos cantan su himno de hip-hop: "Viditown" de forma muy inspiradora.

Al recorrer este documental interactivo e inmersivo y seducidos por estas imágenes esféricas, no podemos menos que detenemos a ver y escuchar estas entrevistas que nos hacen preguntamos que fue del encuadre y el fuera de campo tan sagrado en la vieja escuela audiovisual. La gramática audiovisual propuesta por la llegada de este tipo de nuevas cámaras nos va construyendo un lenguaje donde quien produce las imágenes pierde el control para entregárselo a quien las consume, el usuario navega con su dedo o su mouse a su antojo y define lo que quiere ver: el encuadre, el punto de vista, el plano y el contraplano, los movimientos de cámara como travelings o zoom quedan obsoletos, pues en una imagen esférica que lo ve todo; las paredes de los cuatro costados, el suelo y el techo, las esquinas, la profundidad o lo cercano es el usuario quien decide a dónde mirar y qué cosa escuchar. Combinar o superponer cartografías de Google Street con videos que miran desde las alturas y descienden a gran velocidad hasta el nivel de la calle para mezclarse con traveelings que se mueven por entre el paisaje humano, las casas y las chozas, los comercios y callejuelas es toda una aventura que puedes ver, parar o modificar de trayectoria.

Finalmente, el documental nos lleva al grupo cultural Afro Reggae, que trabaja para que los residentes del Complejo São Carlos vean sus direcciones en Street View por primera vez en la historia. Así es, Junior nos cuenta como esta comunidad no era visible en la plataforma de geolocalización de Google, así que mapea la zona caminándola con una cámara colgada a sus espaldas y dejándonos ver las historias de ese paisaje local donde resalta el artista grafitero, el barbero del barrio o el joven exconvicto que empezó de asaltante adolescente paso por el tráfico de drogas y terminó montando una banda de músicos que hoy escucha toda la favela.

Más de 1,4 millones de personas que viven en favelas no tienen algo tan simple como una dirección. Un punto blanco en el mapa, como lo expresa una de las entrevistadas en uno de los episodios que acompaña el interactivo. Sin calles ni correos, como si no existiéramos, reitera, es el proyecto Tá No Mapa, iniciado en 2012 por la ONG Afro-Reggae con sede en Río de Janeiro y desarrollado en asocio con Google, con un objetivo claro de mapear digitalmente las favelas de la ciudad y generar visibilidad y oportunidades en particular a los comercios marginados y estigmatizados de la gran ciudad. Una invisibilidad cartográfica que remarca la no existencia o el no ser reconocido en ese tejido urbano y simbólico que reclama ser visto, narrado e incluido.

Llama la atención también las múltiples interacciones a monumentos de la ciudad narradas en podcast o galerías fotográficas como el teatro municipal de la música o el museo del futbol del emblemático estadio de Maracaná, a donde podemos dirigirnos simplemente haciendo clic sobre la interfaz mientras el presentador o presentadora en $360^{\circ}$ nos describe el lugar y nos anima a seguir caminando y explorando las calles de Rio a pie o en Street View, con la idea expresada de que en las favelas en cualquier esquina o la vuelta de cualquier calle hay gente que vive y disfruta la vida. El usuario puede entonces quedarse disfrutando los múltiples estilos de vida locales o irse de un lugar a otro y decidir el orden de visualización de los relatos y testimonios que aparecen en los maravillosos parajes de la geografía carioca.

El proyecto, en resumen, es un paso innovador hacia las nuevas formas de pensar las historias locales, inmersivas y con estéticas propias de la red. Un documental multiforme y fluido, que valga decirlo requiere de interés y concentración para ser consumido en su totalidad, no menos de una hora entre bifurcaciones, caminos laberinticos y un logrado experimento de nuevas formas de exhibición para atraer a nuevos espectado- 


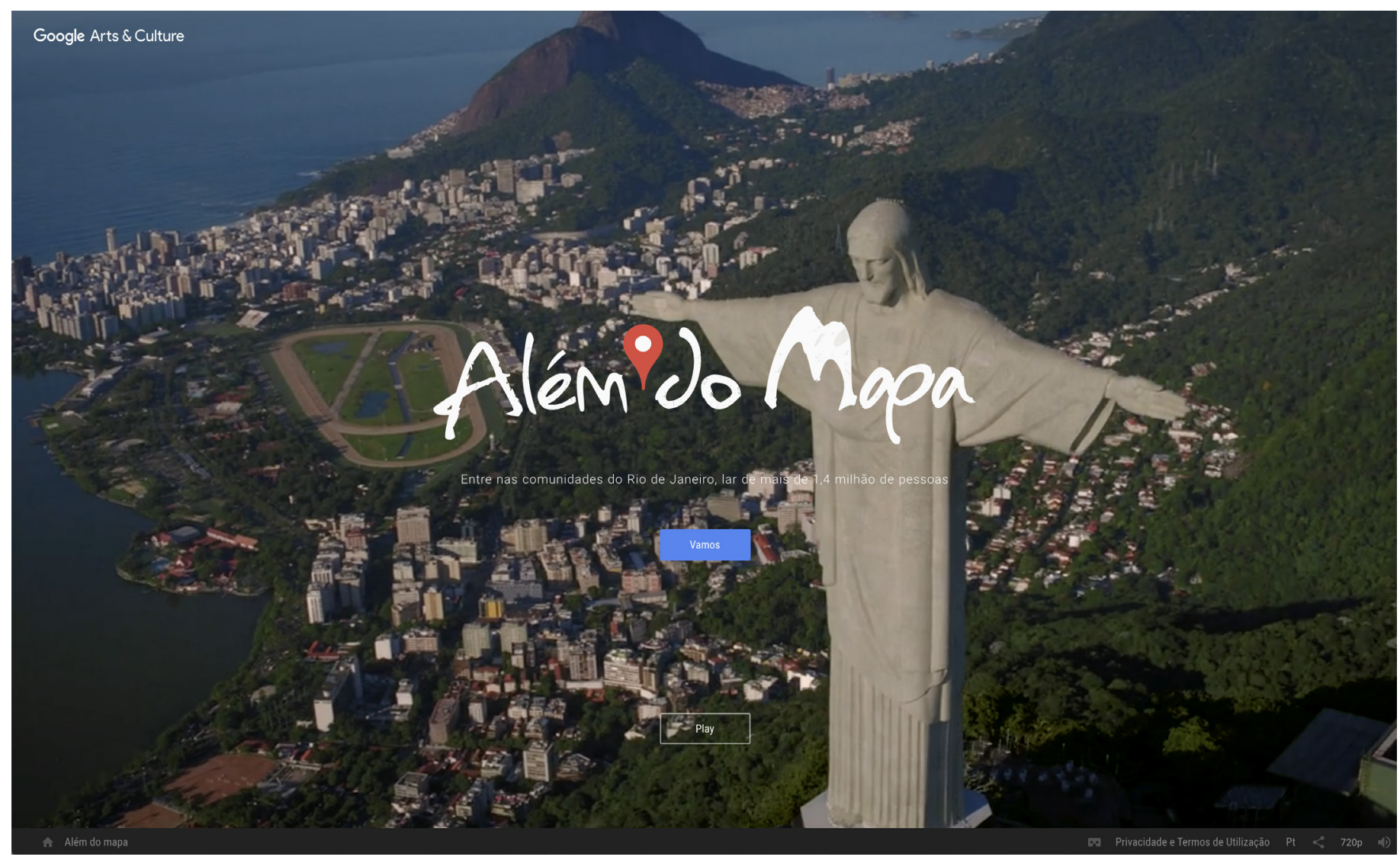

Figura 1. Interfaz de entrada: Beyond the map (Além do Mapa).

res que vienen dejando la cómoda butaca de la sala de cine o el sillón de la televisión en casa por experiencias interactivas y por imágenes fluidas y relatos fragmentados, hipertextuales y multimediales.

\subsection{Mujeres en venta: trata de personas con fines de explotación sexual en Argentina}

Mujeres en Venta². documental transmedia de la serie DocuMedia, producida por la Dirección de Comunicación Multimedial de la Universidad Nacional de Rosario, Argentina, y bajo la dirección de Fernando Irigaray, con guion de Anahí Lovato y la producción de Gisela Moreno, es un ejemplo emblemático y pionero en América Latina del formato de webdoc transmedia.

El formato se mueve entre el periodismo o gran reportaje y el documental. La historia de las mujeres captadas por bandas de trata de personas con fines de explotación sexual propone al espectador un recorrido por múltiples contenidos y formatos de producción. El documental aborda la problemática y nos da diversas versiones y visiones del problema narrado en un modelo de creación interactiva y transmedia que pretende acercar el relato a las nuevas generaciones de usuarios a la información. En principio y como formato matriz o relato núcleo nos entrega un documental para televisión y en formato interactivo, es decir podemos verlo de forma lineal o romper su linealidad desde la interfaz de entrada visto a través de cinco nodos temáticos: captación, las rutas de la trata, explotación, rescate e involúcrate. En este caso el espectador decide en cada momento lo que quiere ver, o qué ruta desea seguir. La interacción está presente durante todo el visionado y la interfaz ofrece alternativas a la ruta secuencial.

Como dice Jenkins: hablar de narrativas transmedia es referirse a relatos que se desarrollan a través de múltiples plataformas mediáticas y cada nuevo texto hace una contribución específica y valiosa a la totalidad del relato... El recorrido por diferentes medios sostiene una profundidad de experiencia que estimula el consumo (2008: pág. 101) Y esto claramente está en la propuesta de "Mujeres en Venta", pues al acceder a la narrativa del proyecto nos encontramos con un mapa interactivo, una serie de cómics impresos y digitales, una galería de fotografías del making-of documental, una campaña gráfica diseñada con realidad aumentada, una serie de episodios o microdocumentales para TV, un libro multiplataforma, una serie de capsulas de videos para pantallas LED que son expuestas en interior y exterior y una serie de movisodios para ser consumidos en dispositivos digitales.

Por otro lado, una experiencia de usuario o fandom es la invitación a participar en la expansión del contenido a través de un mapa colaborativo y georreferenciado con tres categorías propuestas: mujeres desaparecidas, mujeres rescatadas y lugares de explotación. Una pieza interactiva de enorme valor centrada en el periodismo colaborativo, aquel que se construye desde el ciudadano que participa activamente en la producción y generación de los contenidos. 


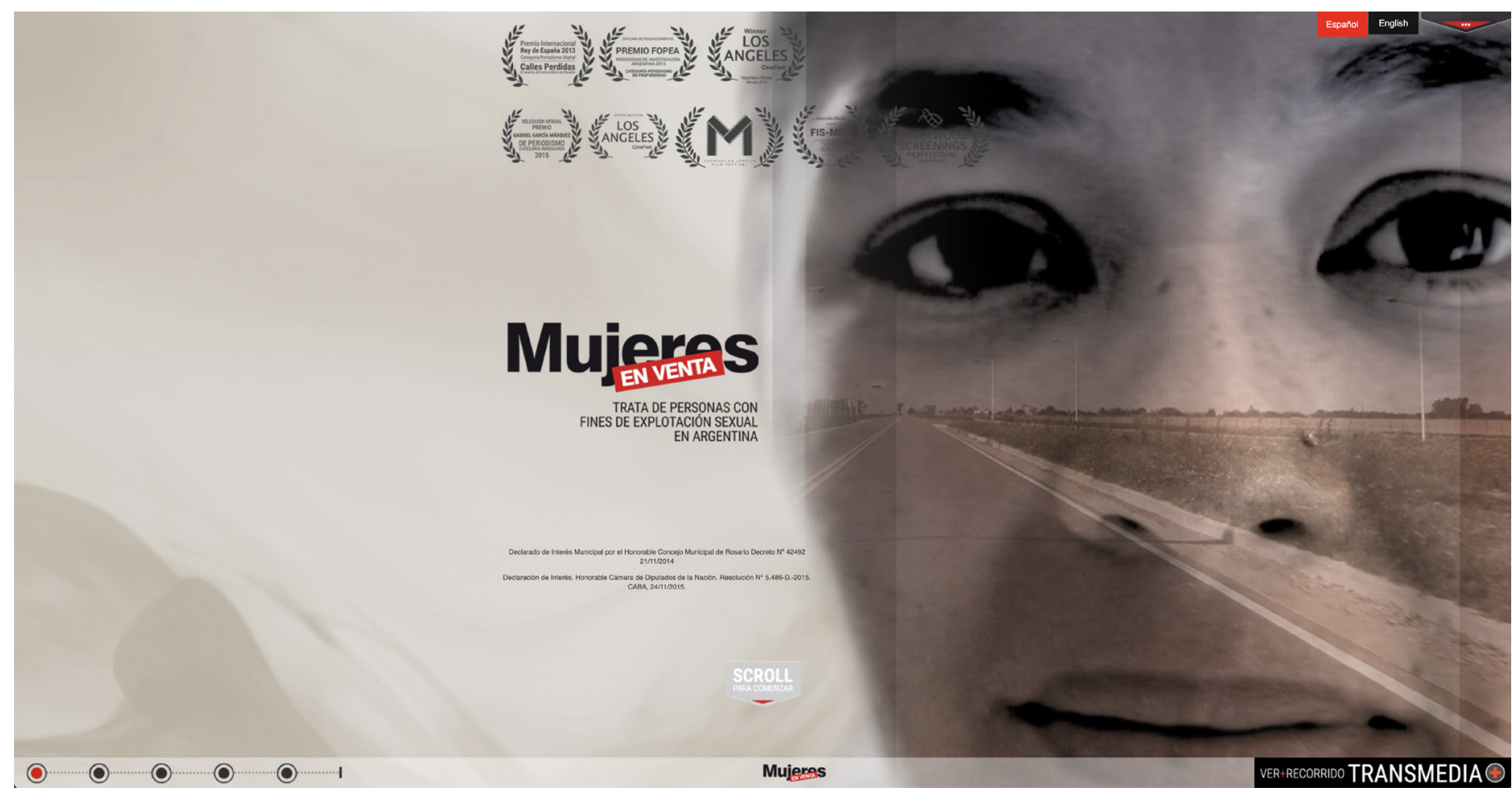

Figura 2. Interfaz de entrada: Mujeres en venta, de Fernando Irigaray, Anahí Lovato y Gisela Moreno.

El usuario puede entrar al mapa para experimentar varios niveles de participación como son el de expresar, denunciar o contribuir al esclarecimiento del hecho delictivo que de fondo nos cuenta este webdoc. Los usuarios pueden observar el registro de las mujeres desparecidas a lo largo y ancho del país con el lugar y la fecha en que cada mujer fue vista por última vez o mirar los procedimientos efectuados para rescatar mujeres en situación de explotación sexual o explorar información sobre cada caso denunciado. Finalmente, revisar los lugares o sitios de explotación sexual como prostíbulos, cabarets, pools, whiskerías, etc. que los mismos ciudadanos pueden denunciar enviando información a través de un enlace.

Mujeres en venta también es periodismo en viñetas en una serie de cómics de cinco capítulos que cuenta la historia de Sofía, una adolescente que logra escapar de una red de trata de personas que la había traído engañada desde Paraguay. Los capítulos fueron publicados con la edición impresa de un semanario local y con las historietas disponibles también en formato digital, para leer en pantalla o descargar en formato pdf.

Otra pieza de este universo narrativo consiste en una campaña callejera con 75 afiches distribuidos en diferentes sitios de la ciudad de Rosario. La propuesta tenía el interés de involucrar a los ciudadanos en la lucha contra la explotación sexual, por esta razón y de forma ingeniosa los productores escondieron un mensaje en realidad aumentada que los transeúntes ocasionales podían descargar desde una aplicación mediante un código QR.
La serie de microrrelatos audiovisuales emitidos por el canal de televisión de la ciudad de Rosario, contenían cuatro piezas de video de cinco minutos de duración con temáticas diferenciadas como Víctimas, Prostíbulos, Redes y Proxenetas. También Historias silenciadas hace parte del entramado narrativo; una pieza documental de 26 minutos producida para la televisión local en una fecha en la que la sociedad argentina salió a las calles para pronunciarse contra la violencia de género y decir \#NiUnaMenos.

El libro multiplataforma es una experiencia colectiva que reúne voces de distintos actores que intervienen en la asistencia a víctimas de trata de personas con fines de explotación sexual: aquí hay textos y entrevistas de funcionarios públicos y especializados; psicólogos y abogados o miembros de organizaciones no gubernamentales -ONG- o de derechos humanos. El libro se editó en versión papel y se puede descargar en formato pdf desde la plataforma.

Los cinco episodios para descarga en dispositivos móviles con una duración de tres minutos, y pensados como serie para canales como YouTube y redes sociales, abordan temáticas como las formas de engaño y reclutamiento de víctimas, el debate entre posturas abolicionistas y reglamentaristas y la problemática de la reinserción social de las mujeres rescatadas.

Finalmente, cierra este universo narrativo una pieza de video diseñada con técnicas de motion graphics para ser proyectada en las pantallas de LED de algunas calles y centros comerciales de la ciudad y que Llamaba la atención a los hombres "clientes" que consideran a las mujeres como mercancía. Un 


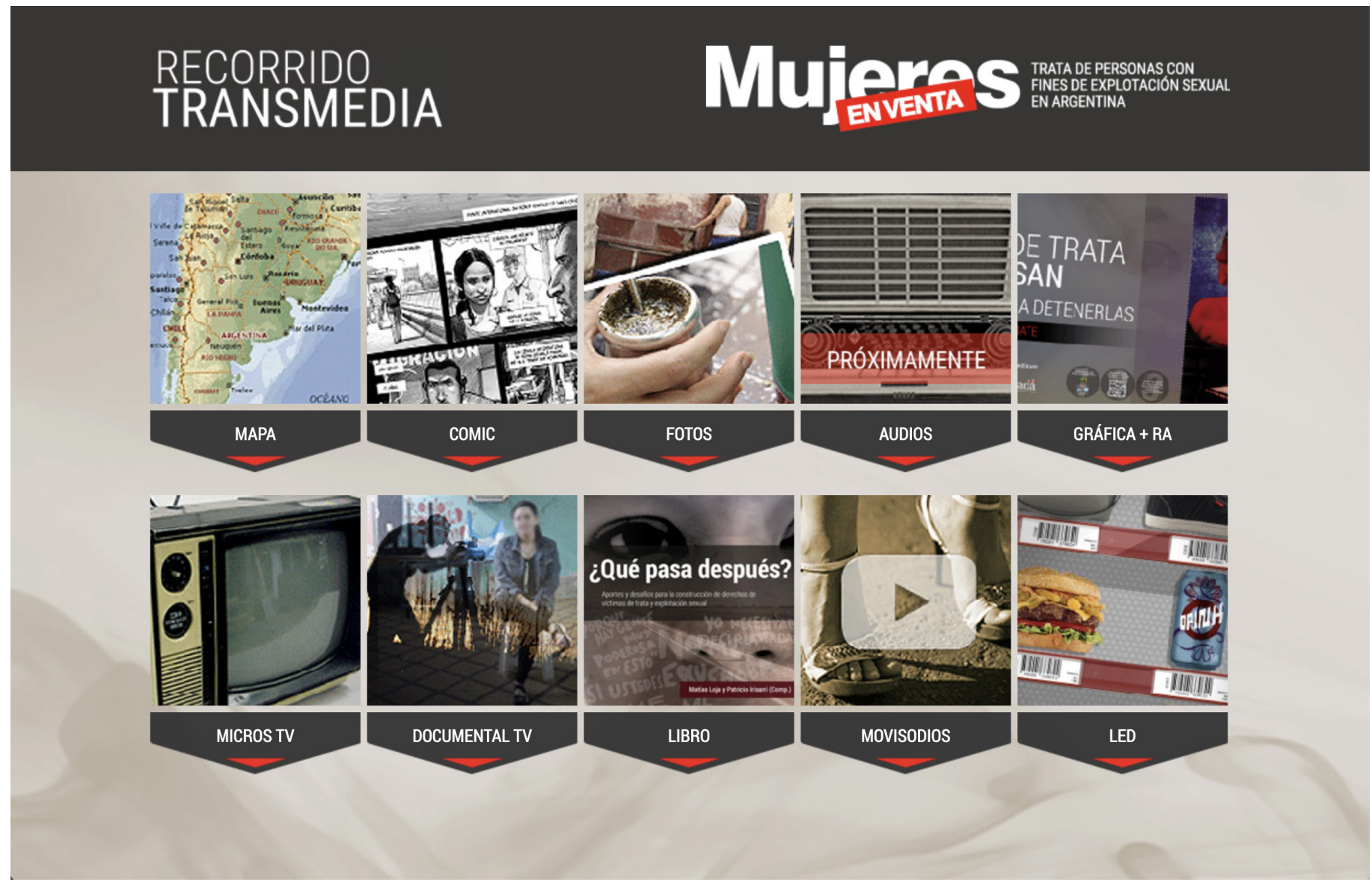

Figura 3. Interfaz Recorrido Transmedia de Mujeres en venta

acierto en la producción de este contenido es el gran valor a la experiencia narrativa al mezclar escenarios digitales y presenciales creando un ecosistema hibrido de fácil consumo para diversos públicos no necesariamente enganchados a los dispositivos y pantallas digitales.

En el webdoc el usuario tiene acceso al universo narrativo intertextual de la captación de mujeres con fines de explotación sexual desde diferentes puntos de entrada, lo que potencia su consumo en diversas tipologías de usuarios, pues cada pieza puede ser entendida sin la necesidad de consumirlas todas y a su vez permite su consumo escalonado que dependerá del propio interés de cada usuario por el contenido, formato y lenguaje utilizado.

\subsection{Pregoneros de Medellín. La web documental interactiva de los que venden cantando en Medellín, Colombia.}

Pregoneros de Medellín ${ }^{3}$ de Ángela Carabalí y Thibault Durand, es también un webdoc o documental interactivo trabajado por un equipo de profesionales independientes por fuera del circuito comercial o convencional y financiado con recursos públicos. El proyecto creado desde una programación de código abierto Open-Source, está hecho a medida utilizando tecnologías como Javascript, Html5 y WebAudio API.
Un código binario inteligente da forma a una polifonía sonora y visual de personajes callejeros, trabajadores itinerantes que pregonan, es decir recitan o cantan los productos que venden en las calles de Medellín, Colombia. El diseño de la interfaz te sorprende de entrada con un gran colorido, música y los cantos o pregones urbanos de los vendedores ambulantes en la monumental plaza del pintor Fernando Botero, lugar turístico de esta ciudad colombiana.

La interfaz te invita a ser recorrida siguiendo las pulsaciones del cursor de tu computador con el que puedes descubrir las 15 historias ocultas en una variedad de personajes que, como dicen los autores entendieron que al cliente, igual que al amor se le seduce por el oído, y a eso le apuestan para vender sus productos en las concurridas calles de esta ciudad de más de tres millones de habitantes.

El documental es una experiencia inmersiva en clave de juego de rol, en tanto te zambulles en ella guiado por una cámara GoPro montada en una bicicleta que te lleva de paseo a través de entrevistas, videos cortos, fotografías y registros sonoros por la cartografía de una ciudad llena de experiencias a pie de calle. Pasear por la calle, disfrutar del paisaje humano y sorprenderse con los pregones (gritos de los vendedores ambulantes) es una experiencia inmersiva, pero vivida como si estuvieses allí caminando con tus zapatos y escuchando con 


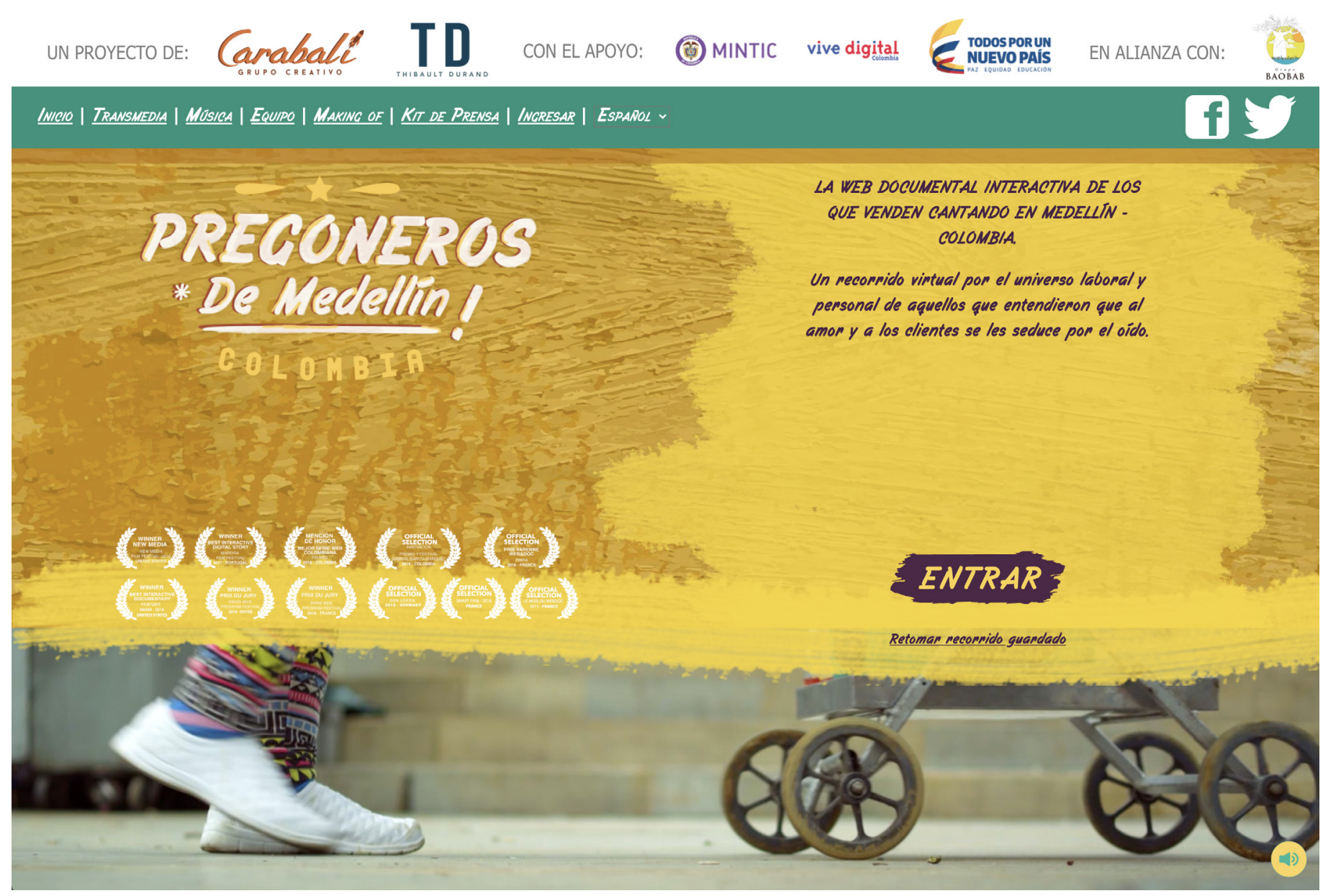

Figura 4. Interfaz de entrada: Pregoneros de Medellín, de Ángela Carabalí y Thibault Durand.

tus oídos cada relato de ese bullicioso paisaje local urbano de esta ciudad.

En el documental, el usuario webactor decide el orden y el tiempo en el que quiere consumir los contenidos. El tiempo narrativo, pues, se construye desde el usuario, pues cada uno decide no solo lo que consume, sino el tiempo de permanencia en cada contenido. La navegación dejada en manos del usuario que define la ruta a seguir para cada contenido imprime un tiempo y un ritmo personalizado, así como una experiencia multiforme y única para cada receptor.

Podríamos decir que este es un modelo de navegación cartográfica, pero es más un road movie pues utiliza Google Maps y Google Street View diseñando su propia cartografía exploratoria a $360^{\circ}$ basada en la exploración de Google Earth, La herramienta proporciona panorámicas a nivel de calle, permitiendo a los usuarios ver partes de la ciudad seleccionadas y sus áreas circundantes a la Plaza Botero centro y origen del recorrido. Street View es navegable con un código propio y hecho a la medida de sus contenidos. Un mapa de geocalización a la izquierda de la pantalla te acompaña durante todos los recorridos para indicarte en qué lugar de la ciudad estás y qué tipo de recorrido estás haciendo en cada momento.
El proyecto también pretende ser un formato transmedia o documental expandido con el diseño y la producción de cápsulas documentales para ser emitidas por la televisión, banda sonora del proyecto, exposiciones interactivas y un proyecto de largometraje documental que espera producirse una vez se encuentre financiación, según lo expresan los productores.

\subsection{Webdoc Transmedia: El Congost visto por el Congost}

Ahora pasaré a hablar de un proyecto de documental interactivo y transmedia desarrollado en un periférico barrio de la provincia de Barcelona, España. No es Latinoamérica, pero la involucra. Ya dije que es una selección arbitraria de documentales latinoamericanos o producidos en Latinoamérica, pero en este caso el webdoc: El Congost visto por el Congost ${ }^{4}$ de Carlos Obando Arroyave, que se produce en Barcelona, España, responde al desarrollo de un proyecto edu-comunicativo y de intervención social, intercultural e interracial que cuenta las experiencias de inmigración de ciudadanos y familias provenientes de Latinoamérica, África y España y que conviven en un barrio periférico de la ciudad de Granolleres en la Provincia de Barcelona.

Lo que empezó como un documental lineal como narrativa núcleo o matriz, en el transcurso de su construcción, rodaje 
y ensamblaje deviene en un formato interactivo y transmedia. El proyecto el Congost se convierte en un webdoc transmedia social y comunitario porque se diseña como una propuesta narrativa para la web, con el ánimo de contribuir a repensar el escenario local-global en el que aparecen los contenidos. Incentiva también las maneras de trabajar la producción audiovisual y sonora desde los mismos ciudadanos retratados y narrados en el documental: nuevas formas de creación, producción y consumo que están emergiendo con la llegada de este formato diseñado para la web, y está dando espacio al diseño de nuevas acciones performativas del audiovisual y a la participación de los ciudadanos en la construcción de sus propios relatos.

En este sentido, este documental se inscribe dentro de esa corriente novedosa del transmedia social o más conocida como activismo transmedia. La experiencia de producción, en primer lugar, identifica una serie de actividades presenciales llevadas a cabo por la comunidad y los colectivos del barrio; mujeres, niños, jóvenes, adultos mayores, inmigrantes. Lo segundo: se nutre de unas experiencias que ya venían sucediendo en el barrio para el diseño de los contenidos en clave documental, fragmentada e interactiva. Y es, justamente, en el trabajo que desarrollan estos colectivos donde nace, por parte de ellos mimos, el interés de sistematizar las experiencias barriales y traducirlas en un formato que pudiera reflejar las maneras de entender los procesos que allí se vivían. Más aún, es en estas interacciones presenciales a partir de un ejercicio nemotécnico y una pedagogía de las emociones, donde se construye colectivamente la idea de un formato documental transmedia con fines pedagógicos dentro del llamado video social.

El webdoc se traza, pues, como un documento audiovisual donde las distintas personas que van desfilando por el formato delante de cámara construyen con sus recuerdos y reflexiones relatos sobre su condición de jóvenes, niños o adultos, sobre el papel que han desempeñado históricamente en el barrio, sobre las personas de mayor edad que se reconocen en los procesos de transformación y organización social que ha vivido el barrio a lo a largo de su historia. La pieza audiovisual es indudablemente un ejercicio y puesta en escena de la memoria individual y colectiva del barrio, pero también de los recuerdos y remembranzas que traen los inmigrantes africanos, latinos y españoles no catalanes, desde sus países o regiones de origen.

La cámara transita de una calle a otra, de un personaje a otro en un recorrido por los lugares que fueron cediendo a la transformación urbanística del entorno; nuevas plazas y parques, nuevas avenidas y calles narradas en un recorrido por el barrio de Congost a través de la mirada de sus propios habitantes y guiados por Secou Cissé, un vecino de origen africano, que nos conduce por el universo multicultural del barrio. Los personajes guían al espectador por los diferentes espacios del barrio, presentan sus amigos y vecinos y van explicando con su voz cada escenario o lugar donde se detiene la cámara, para contagiarse de las costumbres y el colorido multicultural de sus calles y plazas. Los comerciantes hablan de su relación con el barrio como testigos de su trasformación urbanística, las mujeres expresan las relaciones que se construyen en

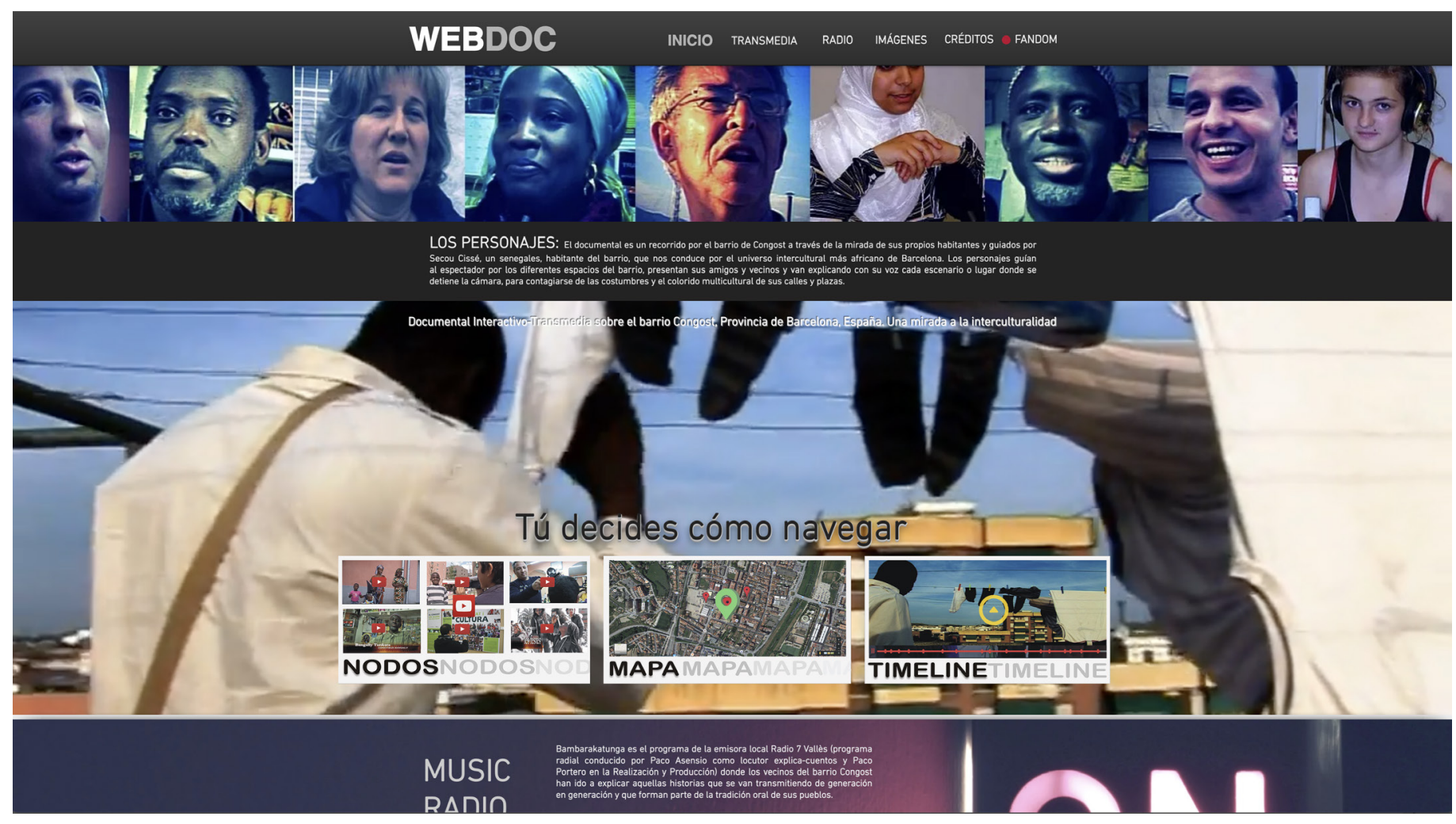

Figura 5. Interfaz Webdoc Transmedia: El Congost visto por el Congost, de Carlos Obando Arroyave. 
el marco de las plazas más emblemáticas o las calles más transitadas, los jóvenes nos cuentan sus dificultades para divertirse o simplemente hacer deporte en un barrio trazado y diseñado desde las oficinas del poder político, los más pequeños nos revelan sus hazañas y nos dejan ver sus sueños y los imaginarios de sus héroes de la pantalla, las mujeres de la asociación de vecinos desvelan pequeñas historias ocultas en esos cuerpos que zapatean al sonido de guitarras y flamencos españoles.

La experiencia documental interactiva se convierte en un contrapeso a las lógicas de exclusión y abre una ventana a la democratización de la comunicación puesto que los contenidos se construyen desde y con las comunidades; tienen que ver de manera directa con sus historias particulares (sus acciones, sus frustraciones, sus deseos, sus necesidades convirtiéndose en actores de su propia historia) El registro documental se convierte en conocimiento útil para estos actores sociales, lo que les permite tener otra perspectiva de los hechos y una contribución a partir de sus propios conocimientos al "potenciamiento" de éstas dinámicas socio-comunitarias en que se encuentran inmersos.

La experiencia se vive ahora en la red como una nueva forma de inteligencia colectiva en la medida que cambian las tradicionales maneras de crear y producir y las dinámicas de consumo del audiovisual. En este caso, el vídeo online con la nueva tecnología streaming y bajo demanda, sienta las bases para el diseño de nuevas maneras de creación, producción, edición de vídeo, creando experiencias colaborativas que contribuyen expandir la narrativa inicial o canon creada para el documental.

El webdoc diseña también el espacio REC, que sirve como plataforma colaborativa invitando a los vecinos del barrio a continuar la expansión del documental subiendo sus propios videos, imágenes o sonidos, mediante herramientas 2.0. Efectivamente, la llegada de cámaras de fotografía y video más ligeras (incluso en teléfonos móviles) asequibles para el gran público y sobre todo de fácil manejo, así como la democratización de las formas de producción y de la copia, con o sin permiso, usando todo tipo de dispositivos que capturan sonidos e imágenes, está permitiendo que un usuario básico, controle todas las etapas de la producción de los contenidos que sube diariamente a la red, o que modifique los contenidos ya subidos por otros usuarios con softwares abiertos y colaborativos. De esta manera el concepto de prosumidor propio de los formatos transmedia define al usuario que mediante tecnologías intuitivas, abiertas, escalables y generalmente gratuitas convierte la red en un territorio para la creación, la producción y, sobre todo, la postproducción.

\subsubsection{Por qué es interactivo, por qué es transmedia el web- doc; el Congost}

En el webdoc el Congost quisimos dejar abiertas las puertas de la navegación al usuario, de tal manera que decidiera cualquiera de las 3 formas de recorrido propuestas. Un sistema nodal, un sistema cartográfico y un sistema timeline.

En el primero la interfaz de la pantalla muestra los diversos nodos temáticos por los que se puede navegar, de esta manera el usuario selecciona su recorrido y lo hace de la manera que más le interesa. En este caso el formato con una característica como la interactividad propone formas de comunicación y difusión abiertas y con lenguajes y fragmentos autónomos de información audiovisual.

La realidad, pues, como un espejo se rompe en mil pedazos y se dispone a ser recuperada en una nueva realidad a base de fragmentos, nodos autónomos de contenido y microdramaturgias, dispersas e hiperconectadas en la pantalla por líneas invisibles que los conectan y por anclajes que los unen en una totalidad recompuesta a capricho del lector-usuario que navega este contenido. Él decide cuántos nodos ve y en qué orden.

El segundo sistema es el modelo cartográfico que funciona a partir de las geolocalizaciones donde se grabaron los diferentes microvideos temáticos que componen el puzle documental, de esta forma el usuario navega por el video de acuerdo con su propio criterio e interés geográfico. El cambio aquí es significativo en tanto el webdoc establece en esta forma de arquitectura una realidad diferente, una realidad mapeada con una mecánica de representación convergente y a su vez independiente. Los elementos, pues, que componen el puzle audiovisual multimedia se conectan de forma tal que pueden ser tan expresivos como la propia navegación que se propone. Es un cambio de mentalidad que desmonta la clásica visión que teníamos en el documental lineal y secuencial, y que nos sometía a una realidad determinada, pensada, estructurada, prefigurada por las líneas secuenciales de la trama, diseñada por los cánones de realidad que producía el mimetismo del formato y la supuesta objetividad del creador del documental.

El tercero es el modelo timeline en la que el usuario puede ver el documental completo de forma lineal o secuencial, como si lo viese en la televisión, pero puede interrumpir su flujo haciendo clic de manera aleatoria en un punto de la línea de tiempo, trazada de inicio a fin, y saltando de un contenido a otro de forma interactiva. Aquí el documental propone una lectura fragmentada y atemporal, construye un recorrido multisecuencial, pues cada usuario lo decide en función de sus necesidades o intereses temáticos planteados en el documental.

Las demás partes del webdoc el Congost son piezas audio-gráfico-visual y navegables a partir del desarrollo del concepto hipertexto propuesto por la arquitectura del nuevo medio Internet. Piezas que abre puertas y ventanas a algo dinámico que se mueve con total propiedad y autonomía, pero 
que se organizan en una estructura orgánica que permite reflexionar sobre el contexto del escenario barrial donde se realiza el documental. Es esto lo que lo hace un documental transmedia, su carácter complejo, su narrativa hiperconectada y su movimiento y flujo de experiencias paralelas en los relatos digitales y las actividades presenciales desarrolladas en el barrio.

Es el caso del programa Bambarakatunga de la emisora analógica y local Radio 7 Vallès, donde los vecinos del barrio han ido a explicar aquellas historias que se van transmitiendo de generación en generación y que forman parte de la tradición oral de sus pueblos de origen. Aquí el documental expande el universo temático del barrio el Congost a partir de la resignificación del valor de estas historias acompañadas de la música de África, Europa o Latinoamérica, según los vecinos invitados provenientes de estos tres continentes. Las historias convertidas en podcast extienden el formato documental más allá de sus propios límites audiovisuales al hacer uso de otros lenguajes, medios y plataformas.

El Congost es un proyecto transmedia también, porque narra la memoria del barrio y sus raíces multiculturales utilizando diversos canales tanto online como off-line; exposiciones itinerantes y participativas de fotografía (Fotomatón), videoclip musical asociado a la temática cultural y musical del África profunda, blogs y espacios virtuales para los colectivos del barrio (http://e-comunitat.blogspot.com/), proyecto socioeducativo con talleres de formación presenciales en técnicas audiovisuales y digitales 2.0, teatro social y participativo con mujeres y jóvenes, actividades en espacios públicos para potenciar grupos de trabajo en música, video y fotografía.

Por tanto, si navegamos el webdoc podemos ver que no es necesario que el espectador haya visto el documental, para entender los podcast de la radio, o el archivo de imágenes de fotomatón, o el libro de papel y digital que los más pequeños del barrio dibujaron e ilustraron escuchando los cuentos que los abuelos les explicaban a partir de su tradición oral, o los cuentos narrados por los propios niños y niñas del barrio, que también se subieron a un formato de audio libro y que pueden ser escuchados y entendidos por sí solos. O el videoclip del músico senegalés que dio paso a la banda sonora del documental, o, finalmente, las cápsulas documentales que se integran al documental lineal, pero que a su vez son un producto audiovisual independiente, y que permite mediante nodos temáticos (las personas, los espacios del barrio) navegar por el webdoc sin ser consumidas en su totalidad.

La web es, pues, el mejor medio para diseñar una estrategia narrativa y creativa como esta que usa tecnologías y sistemas de comunicación en los cuales no se trata tan solo de juntar y conectar lenguajes y soportes o expandirlos por las marañas tecnológicas de la red, sino además construir el universo narrativo del barrio el Congost desde su propia comunidad mediante un activismo transmedia que aprende a usar tec- nologías de código abierto y prototipos desarrollados con plataformas Open Source y 2.0.

\subsection{Narrar en clave local, ver en clave global}

La experiencia cognitiva, la experiencia estética y la experiencia tecnológica de este formato de webdoc que analizamos, nos señala un nuevo imaginario o espacio mental de manera metafórica en tanto la pantalla simulacro del encuadre predeterminado o de la fotografía del documental lineal o tradicional ahora se disuelve en esa distancia y espacio que se construye entre la teché y episteme, entre el sujeto que mira y el objeto mirado.

Efectivamente, en estos lenguajes digitales del webdoc el concepto de inmersión y de interacción (accionar el mouse, desplazarse en la pantalla con el teclado, clicar y decidir el contenido que se quiere ver, adelantar, parar o congelar una imagen) propone una nueva realidad construida, personalizada, diseñada por cada usuario, así la realidad 'pura e ingenua' del retrato del autor se disuelve en una multiplicidad de realidades que van más allá de lo que el programador-creador imagina.

En estos cuatro ejemplos vinculados a Latinoamérica que he enumerado, el webdoc construye un espacio completamente diferente al que estábamos acostumbrados, pues el texto interactivo da paso a un flujo de lo expandido on y off-line, de lo real/imaginario, un espacio de realidad muchísimo más complejo que la realidad lineal a la que estábamos acostumbrados y que veníamos contando en el documental secuencial del cine y la televisión. Aquí, por el contrario, las diferentes capas narrativas se superponen una tras otra o una sobre otra, creando un relato de complejidad mayor y con múltiples lecturas y resignificaciones. Es un cambio de mentalidad, forzosamente, un nuevo significado regido ahora por la fragmentación de una meta estructura en la que la organización de los archivos o de la memoria retratada no es la fiel copia metonímica de esa realidad captada por la lente de la cámara, sino más bien una metáfora expandida que no se corresponde con la linealidad que usábamos para entender o acercarnos al mundo visible y real.

En efecto, la pantalla muestra un campo de exploración que no teníamos antes, en tanto utiliza estrategias narrativas que no son captadas obligatoriamente por la cámara: mapas conceptuales, datos, gráficos, infografías, dibujos, animaciones, textos y todo aquello que no se muestra de manera evidente, pero que subyace en el trazo del recorrido de este sistema reticular basado en el hipertexto; nuevos racord, empalmes, fricciones dramatúrgicas, superposiciones, alternancias, propiedades todas éstas del relato expandido y transmediático que se construye desde ese código creativo que conecta múl- 
tiples lenguajes, diversas plataformas y varios sentidos.

Para concluir, el nuevo formato de la web con sus características como la interactividad, la hipertextualidad y la transmedialidad que conecta contenidos a través de un sistema red en una multiplicidad de plataformas y canales, lo que se propone no es otra cosa que pasar de una comunicación lineal a una comunicación interactiva, expandida, colaborativa y transmedia, en la que cada medio como dice $\mathrm{H}$. Jenkins (2003), hace lo que mejor sabe hacer y en la que cada uno de los contenidos en cada plataforma es autosuficiente y genera un consumo autónomo de un universo narrativo complejo y fragmentado.

\section{Notas al final}

1. Beyond the map (Além do Mapa): https://beyondthemap.withgoogle.com/pt-br/

2. Mujeres en venta: http://www.documedia.com.ar/mujeres

3. Pregoneros de Medellín. https://pregonerosdemedellin.com

4. Webdoc Transmedia: El Congost visto por el Congost. https://www. webdoctransmedia.com

\section{Bibliografía}

Bernardo, N. (2014). Transmedia 2.0: How to Create an Entertainment Brand Using a Transmedial Approach to Storytelling. BeActive books London.

Castells, M. (2009). Comunicación y Poder. Alianza Editorial.

Castells, M., (2001). La galaxia Internet. Plaza \& Janés.

Gifreu, A. (2014). El documental interactivo. Evolución, caracterización y perspectiva de desarrollo. UOC Press.

Gifreu, Arnau. (2010). El documental multimèdia interactiu. Una proposta de model d'anàlisi (Trabajo de investigación). Barcelona: Universitat Pompeu Fabra. https://repositori.upf.edu/bitstream/ handle/10230/11346/TFM_Gifreu. pdf?sequence=1氏isAllowed=y

Finquelievich, S. (Ed.) (2000). !Ciudadanos, a la Red! Los vínculos sociales en el ciberespacio. La Crujía.

Fernández Guerra, V. (Ed.) (2015). Revisitando el cine documental: de Flaherty al webdoc. Sociedad Latina de Comunicación Social.

Flores, J. y Porto, D. (2012). Periodismo Transmedia. Reflexiones y técnicas para el ciberperiodista desde los laboratorios de medios interactivos. Fragua.

Irigaray, F. y Lovato, A. (Eds.) (2014). Hacia una comunicación transmedia. UNR Editora.

Irigaray, F. y Lovato, A. (Eds.) (2015). Producciones transmedia de no ficción. Análisis, experiencias y tecnologías. UNR Editora.

Irigaray, F. (2015). Periodismo Transmedia: Nuevas posibilidades narrativas y de experiencia de usuario. En Roitberg, G. y Piccato, F. (Eds.) Periodismo disruptivo. Dilemas y estrategias para la innovación (pp. 167-172). La Crujía.

Jenkins, H. (2008). Convergence Culture. La cultura de la convergencia de los medios de comunicación. Paidós.

Jenkins, H. (2006). Fans, bloggers, and gamers: Exploring participatory culture. New York University Press.
Lévy, P. (2004). Inteligencia colectiva: por una antropología del ciberespacio. La Découverte.

Lovato, A. (2013). La proyección multimedia como herramienta en la comunicación. Recuperado de http://www.unr.edu.ar/noticia/7473/ la-proyeccion-multimedia-comoherramienta-en-la-comunicacion

Nadin, M. (2003). Aesthetics. En Vilanova, M. y Chorda, F. (eds.) A Mind at Work. We Are Our Questions (pp. 167-188). Synchron.

Obando, C. (2012). De las TIC al DCC: Tecnologías de la Información y la Comunicación, el nuevo escenario para el desarrollo cultural comunitario. Editorial Académica Española.

Obando, C. (2017). Perversiones digitales; Ciberactivismo, Producción Transmedia y Cultura hacker. Editorial Universidad de Antioquia. Medellín.

Pavlik, J. V. (2005). El periodismo y los nuevos medios de comunicación. Paidós.

Piscitelli, A. (2002). Meta-Cultura. La Crujía.

Sierra, F. (Ed.) (2013). Ciudadanía, tecnología y cultura. Gedisa.

Scolari, C. (2004). Hacer clic: hacia una sociosemiótica de las interacciones digitales. Gedisa.

Scolari, C. (2008). Hipermediaciones. Elementos para una teoría de la Comunicación Digital Interactiva. Gedisa.

Sora, C. (2016). Radiografia del webdoc a Catalunya: obres i autors. Grup DigiDoc. https://hdl.handle.net/10230/27483

Vilches, L (2001). La migración digital, Gedisa.

Vilches, L. (Coord.) (2013). Convergencia y transmedialidad: la ficción después de la TDT en Europa y Latinoamérica. Gedisa.

\section{CV}

Carlos Obando Arroyave. Doctor (Universidad Ramón Llull, 2007) en Investigación Pedagógica y TIC especialista en tecnologías de la información y la comunicación en comunidades y redes sociales locales. Estudios de Posgrado en Comunicación Audiovisual Digital (Universidad Internacional de Andalucía, 2002). Especialista en Semiótica-Estética, Universidad Nacional, Colombia. Comunicador Social-Periodista, Universidad de Antioquia, Colombia. Investigador de la Cátedra UNESCO de "Educación, Desarrollo, Tecnología y Sistemas de Financiación en Latinoamérica" entre 2001/05, en Barcelona, España. Fue creador e investigador de la Maestría en Narrativas y Producción Transmedia y de la Maestría en Producción Audiovisual de la Universidad Autónoma de Barcelona, España, entre 2007 y 2016. Ha sido investigador, conferenciante y docente en comunicación audiovisual e interactiva y transmedia, periodismo digital y comunicación 2.0 en España y Latinoamérica. Actualmente es director de la plataforma de Periodismo digital y transmedia www.directobogota.com/ y director del Posgrado en Televisión Expandida y Transmedia. Profesor-Investigador del Departamento de Comunicación de la Facultad de Comunicación y Lenguaje, Pontificia Universidad Javeriana, Bogotá Colombia. Es Autor y coautor de varios libros sobre Internet, comunicación digital y transmedia. 